\begin{tabular}{lcccr} 
T H E & A R C H I V E & O F & M E C H A N I C A L & E N G I N E E R I N G \\
\hline VOL. LVIII & 2011 & Number 4
\end{tabular}

10.2478/v10180-011-0028-0

Key words: stress intensity factors, extended-finite element method, shifted basis approximation

PAWEŁ STĄPÓR *

\title{
APPLICATION OF XFEM WITH SHIFTED-BASIS APPROXIMATION TO COMPUTATION OF STRESS INTENSITY FACTORS
}

\begin{abstract}
The essential parameters for structure integrity assessment in Linear Elastic Fracture Mechanics (LEFM) are Stress Intensity Factors (SIFs). The estimation of SIFs can be done by analytical or numerical techniques. The analytical estimation of SIFs is limited to simple structures with non-complicated boundaries, loads and supports. An effective numerical technique for analyzing problems with singular fields, such as fracture mechanics problems, is the extended finite element method (XFEM).

In the paper, XFEM is applied to compute an actual stress field in a twodimensional cracked body. The XFEM is based on the idea of enriching the approximation in the vicinity of the discontinuity. As a result, the numerical model consists of three types of elements: non-enriched elements, fully enriched elements (the domain of whom is cut by a discontinuity), and partially enriched elements (the so-called blending elements). In a blending element, some but not all of the nodes are enriched, which adds to the approximation parasitic term.

The error caused by the parasitic terms is partly responsible for the degradation of the convergence rate. It also limits the accuracy of the method. Eliminating blending elements from approximation space and replacing them with standard elements, together with applying shifted-basis enrichment, makes it possible to avoid the problem. The numerical examples show improvements in results when compared with the standard XFEM approach.
\end{abstract}

\section{Introduction}

The extended finite element method, first introduced by Belytschko and Black [2] and Möes et al. [6], provides an effective tool for analyzing discontinues and singular problems. It operates through augmenting standard finite element approximation with additional functions containing the information about the solution. In the XFEM, the enriched domain is limited only to the

* Faculty of Management and Computer Modelling, Kielce University of Technology, Al. Tysiaclecia Państwa Polskiego 7, 25-314 Kielce, Poland; E-mail: stapor@eden.tu.kielce.pl 
vicinity of a crack, and differently than in the standard finite element method, the mesh does not have to align with a discontinuity. However, the method is not free from drawbacks. The main source of error arises from unwanted terms in blending elements, which are partially enriched, thus the enrichment function cannot form a partition of unity. Chessa et al. [3] eliminated the parasitic terms by applying the assumed strain method in blending element. Degrees of freedom gathering technique and higher order elements have also been shown to improve the accuracy in the blending elements, Laborde et al. [5]. Tarancòn et al. [8] proposed enhanced blending elements with a fixed enrichment area. A linearly decreasing weight function over transition layer eliminates the partially enriched elements, so that partition of unity property can be satisfied everywhere, Fries [4].

In the paper, the shifted-basis enrichment (Ventura et al. [9], $\mathrm{Zi}$ et al. [11]) is applied together with modification of the approximation in blending elements. The shifted-basis enrichment is introduced in order to make the degrees of freedom of a node in a fully enriched element the physical solution of the nodal displacement. Thus, the approximation in blending elements can be reduced to standard finite element approximation as long as the enrichment function is the same or of a lower order than the partition of the unity function. Nevertheless, for higher order functions, the following modifications together with removing the enriched parts in blending elements provide an improvement in computed values of SIFs. To extract the SIFs, a well known in fracture mechanics $J$-integral, Rice [7], and the domain form of the interaction integral, Yau et al. [10], are applied. For the purposes of the analysis, a corresponding MATLAB program is developed. A classic problem of fracture mechanics is used as a benchmark.

In Section 2, the model problem considered is defined, which is relative to the equilibrium of a cracked body in plane linear elasticity. Section 3 and 4 describes standard and shifted-basis XFEM approximation for the problem, respectively. The properties of the approximation in blending elements are presented in Section 5. In the next Section 6, simple patch test is described. Section 7 presents the method of calculation of stress intensity factors. The results of the test for the benchmark problems are presented in Section 8.

\section{Problem formulation}

A linear elasticity problem is addressed, with isotropic homogeneous material, on a two-dimensional cracked domain $\Omega$. On the part of the boundary $\Gamma_{D}$, the Dirichlet condition is prescribed, and the Neumann condition is defined on $\Gamma_{N}$. The crack $\Gamma_{C}$ is assumed to be traction free. The boundary $\Gamma$ is composed of the sets $\Gamma_{D}, \Gamma_{N}$ and $\Gamma_{C}$, such that $\Gamma=\Gamma_{D} \cup \Gamma_{N} \cup \Gamma_{C}$. 
In order to describe the displacement asymptotic field near the crack tip, local polar co-ordinates $(r, \theta)$ defined at the crack tip are introduced (Fig. 1), where denotes the distance from the crack tip.

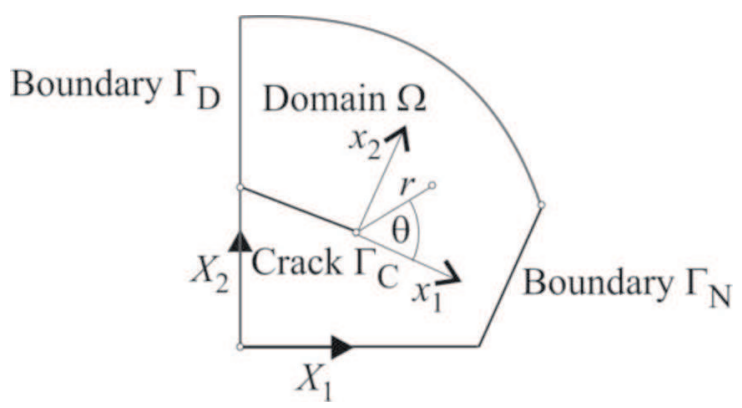

Fig. 1. A cracked body with polar co-ordinates relative to the crack tip

The equilibrium of the body is expressed by the virtual work principle:

$$
\int_{\Omega} \boldsymbol{\sigma}(\boldsymbol{u}): \boldsymbol{\varepsilon}(\boldsymbol{w}) \mathrm{d} \Omega=\int_{\Omega} \boldsymbol{p} \cdot \boldsymbol{w} \mathrm{d} \Omega+\int_{\Gamma_{N}} \boldsymbol{t} \cdot \boldsymbol{w} \mathrm{d} s
$$

where

$\boldsymbol{\sigma}(\boldsymbol{u}), \boldsymbol{\varepsilon}(\boldsymbol{w})$ - stress and strain tensors,

$\boldsymbol{p}, \boldsymbol{t}$ - force densities on $\Omega$ and $\Gamma_{N}$, respectively.

The constitutive relation is given by the Hooke's law:

$$
\sigma(u)=C: \varepsilon(w)
$$

where $\boldsymbol{C}$ is the Hooke tensor.

In the present study, small strains and displacements are considered, expressed by the strain-displacement relation:

$$
\boldsymbol{\varepsilon}(\boldsymbol{u})=\nabla(\boldsymbol{u})
$$

where $\nabla$ is the symmetric part of the gradient operator.

\section{Standard XFEM approach}

The XFEM approximation consists of a standard finite element part $\boldsymbol{u}(\boldsymbol{x})_{C}$ and the enriched part $\boldsymbol{u}(\boldsymbol{x})_{E}$ that enables the approximation to capture solution characteristic in the vicinity of the discontinuity

$$
u(x)=u(x)_{C}+u(x)_{E}
$$

where

$$
\boldsymbol{u}(\boldsymbol{x})_{C}=\sum_{i \in I} N_{i}(\boldsymbol{x}) q_{i}
$$


The enrichment term $\boldsymbol{u}(\boldsymbol{x})_{E}$ combines the partition of unity (PU) function with the enrichment functions

$$
\boldsymbol{u}(\boldsymbol{x})_{E}=\sum_{j \in J} \sum_{\alpha=1}^{n} N_{j}(\boldsymbol{x}) \boldsymbol{\Psi}^{\alpha}(\boldsymbol{x}) a_{j}^{\alpha}
$$

where $\Psi^{\alpha}(x)$ are enrichment functions, $N_{j}(\boldsymbol{x})$ are the PU functions, $J$ is the set of nodes enriched by $\Psi^{\alpha}(\boldsymbol{x})$ and $a_{j}^{\alpha}$ are the unknowns associated with the node $j$ and the enrichment functions $\Psi^{\alpha}(\boldsymbol{x}) . I$ is the set of all nodes.

Application of XFEM to LEFM problems relies on enriching standard FE displacement approximation with two additional types of functions, namely, Heaviside step function $H(x)$, which represents the discontinuity across the crack, and the function $\boldsymbol{F}(\boldsymbol{x})$ which spans approximately the Wastergaard solution of the crack tip asymptotic displacement field. The Haeviside function is defined as

$$
H(x)=\left\{\begin{array}{lll}
-1 & \text { if } & \varphi(x)<0 \\
+1 & \text { if } & \varphi(x) \geq 0
\end{array}\right.
$$

where $\varphi(\boldsymbol{x})$ is the signed distance function, usually determined with the help of Level Set Method, Ventura et al. [9]. Wastergaard solution is represented by four basis functions in the form

$$
\boldsymbol{F}(\boldsymbol{x})=\left\{\sqrt{r} \sin \frac{\theta}{2}, \sqrt{r} \cos \frac{\theta}{2}, \sqrt{r} \sin \frac{\theta}{2} \sin \theta, \sqrt{r} \cos \frac{\theta}{2} \sin \theta\right\}
$$

where $r$ and $\theta$ are the local polar coordinates.

Figure 2 presents enrichment strategy on the example of a rectangular mesh with an arbitrary crack.

The enrichment strategy is governed by two rules. If an element contains the crack tip, all the nodes are additionally enriched by $\boldsymbol{F}(\boldsymbol{x})$ (the crack tip element, Fig. 2). The elements which are entirely cut by the crack, but do not adjoin the crack tip element, are enriched by $H(x)$ function. The enrichment in the rest of elements depends on the type of nodes belonging to an element. In the case, when an element contains nodes enriched by $\boldsymbol{F}(\boldsymbol{x})$ or $H(\boldsymbol{x})$ (in some cases $\boldsymbol{F}(\boldsymbol{x})$ and $H(\boldsymbol{x}))$, the approximation takes it into account.

The approximation for non-enriched elements takes the standard FE form

$$
\boldsymbol{u}(\boldsymbol{x})=\sum_{i \in I} N_{i}(\boldsymbol{x}) q_{i}
$$

where $N_{i}(\boldsymbol{x})$ are the classical FE shape functions and $I \in\{1,2,3,4\}$ is the set of all nodes in an element, Fig. 3a. 


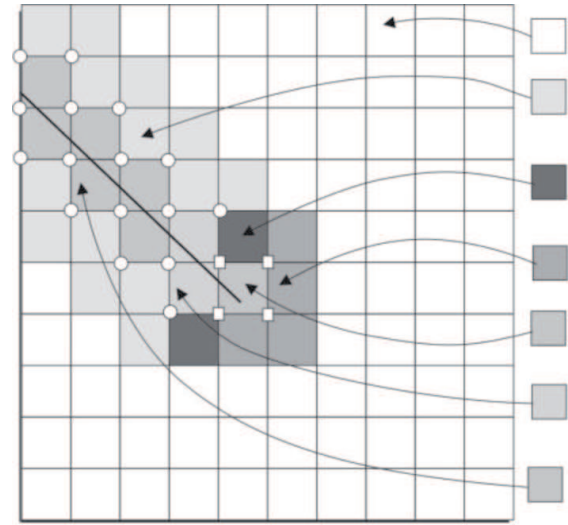

Non-enriched elements

Blending elements partially enriched by $H(\mathbf{x})$

Blending elements partially enriched by $H(\mathbf{x})$ and $F(\mathbf{x})$ Blending elements partially enriched by $F(\mathbf{x})$ The crack tip element Elements enriched by $H(\mathbf{x})$ and $F(\mathbf{x})$

Elements totally enriched by $H(\mathbf{x})$

- Nodes enriched by $H(\mathbf{x})$

- Nodes enriched by $F(\mathbf{x})$

Fig. 2. The enrichment strategy

a) Non-enriched element

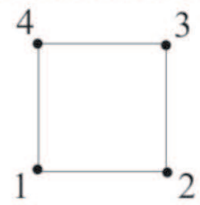

c) The crack tip element

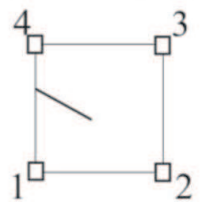

e) Blending element partially enriched by $H(\mathbf{x})$

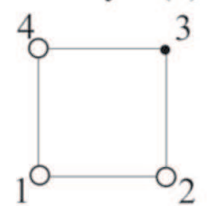

b) Element totally enriched by $H(\mathbf{x})$<smiles>OC1OC2OC1O2</smiles>

d) Element enriched by $H(\mathbf{x})$ and $F(\mathbf{x})$

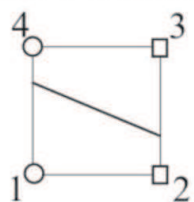

f) Blending element partially enriched by $H(\mathbf{x})$ and $F(\mathbf{x})$

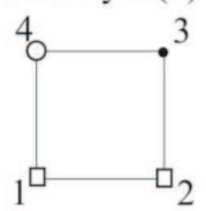

g) Blending element partially enriched by $F(\mathbf{x})$

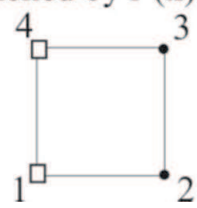

Fig. 3. Types of elements in a mesh 
If the element is entirely cut by a crack, all the nodes are additionally enriched with Heaviside function $H(x)$, Fig. $3 b$

$$
\boldsymbol{u}(\boldsymbol{x})=\sum_{i \in I} N_{i}(\boldsymbol{x}) q_{i}+\sum_{i \in I} N_{i}(\boldsymbol{x}) H(\boldsymbol{x}) b_{i}
$$

where $b_{i}$ are Heaviside enrichment degrees of freedom.

For the element which contains the crack tip, the discontinuity is represented by Westergaard's solution, the approximation in this case takes the form, Fig. 3c

$$
\boldsymbol{u}(\boldsymbol{x})=\sum_{i \in I} N_{i}(\boldsymbol{x}) q_{i}+\sum_{i \in I} \sum_{\alpha=1}^{4} N_{i}(\boldsymbol{x}) \boldsymbol{F}^{\alpha}(\boldsymbol{x}) a_{i}^{\alpha}
$$

where $a_{i}^{\alpha}$ are the corresponding degrees of freedom for a node $i$ (four in each direction).

The transition elements contain both kinds of enrichment, some nodes are additionally enriched by Heaviside function and some nodes are enriched by Wastergaard's basis function. Figure $3 \mathrm{~d}$ shows an example element of that type. The approximation now takes the following form

$$
\boldsymbol{u}(\boldsymbol{x})=\sum_{i \in I} N_{i}(\boldsymbol{x}) q_{i}+\sum_{i \in I} N_{j}(\boldsymbol{x}) H(\boldsymbol{x}) b_{j}+\sum_{k \in K} \sum_{\alpha=1}^{4} N_{k}(\boldsymbol{x}) \boldsymbol{F}^{\alpha}(\boldsymbol{x}) a_{k}^{\alpha}
$$

where sets $J \in\{1,4\}$ and $K \in\{2,3\}$ contain the nodes enriched with $H(x)$ and $\boldsymbol{F}^{\alpha}(\boldsymbol{x})$, respectively.

The sets of nodes enriched in blending elements do not contain all element's nodes. The approximation formula for blending elements partially enriched by $H(x)$, Fig. 3e takes the form of Eqn (12) with $J \in\{1,2,4\}$ and $K \in\{$ empty\}, for blending elements partially enriched with both $H(x)$ and $\boldsymbol{F}^{\alpha}(\boldsymbol{x})$ Fig. 3f the sets are: $J \in\{4\}, K \in\{1,2\}$ and for blending elements partially enriched by $\boldsymbol{F}^{\alpha}(\boldsymbol{x}): J \in\{$ empty\}, $K \in\{1,4\}$, Fig. $3 \mathrm{~g}$.

\section{Shifted basis approximation}

Standard FE approximation fulfils the Kronecker property, which leads to desirable features, namely the computed unknowns $q_{i}$ are directly the values of displacement at the node $i$, thus imposing the Dirichlet boundary condition $u_{D}(\boldsymbol{x})$ is simple $q_{i}=u_{D}\left(\boldsymbol{x}_{i}\right)$. In the standard XFEM approximation, these conditions do not hold. That can be achieved by modifying the enrichment function $\Psi(x)$ as

$$
\boldsymbol{\Psi}_{\text {Shift }}(\boldsymbol{x})=\boldsymbol{\Psi}(\boldsymbol{x})-\boldsymbol{\Psi}\left(\boldsymbol{x}_{j}\right)
$$


which shifts the basis functions to zero point at each enriched node $\left(\boldsymbol{\Psi}_{\text {Shift }}\left(\boldsymbol{x}_{j}\right)=0\right)$. Now, the enrichment term is given by

$$
\boldsymbol{u}(\boldsymbol{x})_{E}=\sum_{j \in J} \sum_{\alpha=1}^{4} N_{j}(\boldsymbol{x}) \boldsymbol{\Psi}_{\text {Shift }}^{\alpha}(\boldsymbol{x}) a_{j}^{\alpha}
$$

which leads to the desired property $\boldsymbol{u}(\boldsymbol{x})_{E}=0$.

\section{Blending elements}

In elements where only some of their nodes are enriched, functions $N_{j}(\boldsymbol{x})$ do not build a partition of unity, i.e.

$$
\sum_{j \in J} N_{j}(\boldsymbol{x}) \neq 1
$$

In consequence, the enrichment function cannot be reproduced exactly in these elements, which can lead to large errors and poor global convergence. In particular, when XFEM is applied to linear elastic fracture mechanics, the parasitic terms in the approximation space of blending elements yield a decrease in accuracy of computed stress intensity factors. The enriched part in approximation formula, Eqn (12), generates pathological term, which cannot be compensated by standard FE approximation.

However, in blending elements partially enriched by $H(x)$, Heaviside enrichment part occurs only. In such a case, Heaviside function has always the same sign at each integration point of the element, i.e. $H(x)=+1$ or $H(\boldsymbol{x})=-1$. Applying shifted-basis approximation leads to the fallowing formula

$$
\boldsymbol{u}(\boldsymbol{x})=\sum_{i \in I} N_{i}(\boldsymbol{x}) q_{i}+\sum_{j \in J} N_{j}(\boldsymbol{x})\left(H(\boldsymbol{x})-H\left(\boldsymbol{x}_{j}\right)\right) b_{j}
$$

Thus, in the expression (16) the term $H(\boldsymbol{x})-H\left(\boldsymbol{x}_{j}\right)$ is always 0 , what resolves the problem with parasitic terms in that kind of elements.

For blending elements partially enriched by $F(\boldsymbol{x})$ the pathological terms consist of the higher order function. In the paper, that term is eliminated, what is equivalent to removing the blending elements and replacing them with non-enriched elements. Unfortunately, that leads to a non-conforming mesh. However, applying, at the same time, the shifted-basis approximation, enforces continuity of the displacement at nodes connecting totally enriched elements with non-enriched elements. 


\section{Bi-material bar: patch test}

In order to demonstrate the difference between standard XFEM approach and the XFEM with the proposed modification, one dimensional bi-material bar is considered, Fig. 4. The bar of the length $L$ and the cross section area $A$ is made of two materials defined by Young's module $E_{1}$ in the left part of the bar, and $E_{2}$ in the right part. The interface runs through the point $x^{*}=L / 2$. Concentrated force $P$ acts at $x=L$ and the displacement $u(0)=0$ is prescribed.

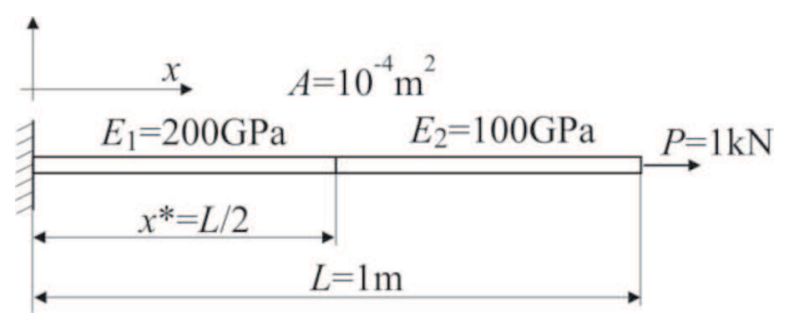

Fig. 4. Bi-material bar

The exact solution to the problem is shown in Fig. 5. The displacement $u(x)$ is represented by a piecewise linear function, with a kink at $x^{*}$.
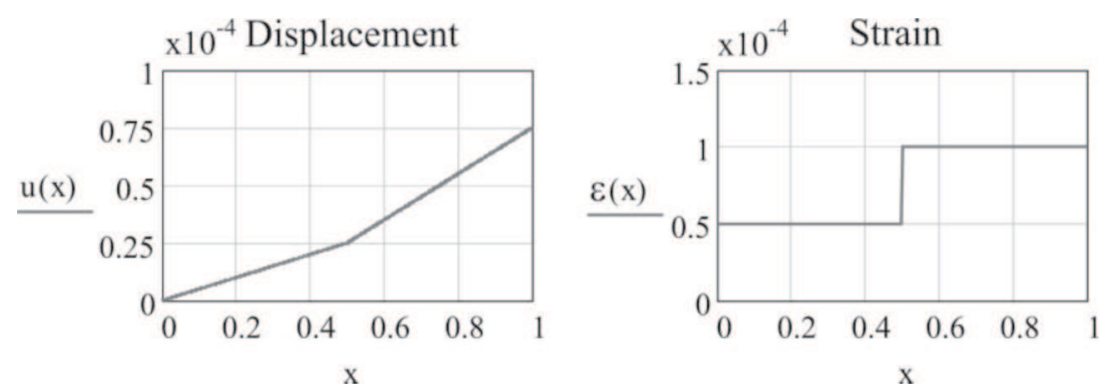

Fig. 5. Analytical solution

\subsection{Standard XFEM solution}

The domain is divided into five equal-length finite elements, Fig. 6. Discontinuity goes across element 3 , so nodes 3 and 4 are enriched. Thus, the elements 2 and 4 are blending elements. The enriched nodes are marked with square.

For the standard XFEM, the global enrichment function is chosen in the form

$$
\psi(x)=\left|x-x^{*}\right|
$$




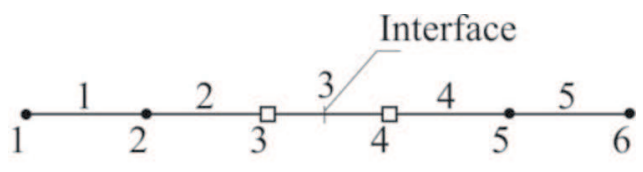

- Standard FE node $\square$ Enriched node

Fig. 6. Discretized domain

The PU functions are the classical FE linear shape functions

$$
N(x)=\left[1-\frac{x-d^{e}}{l^{e}} \frac{x-d^{e}}{l^{e}}\right]
$$

where $d^{e}$ and $l^{e}$ are the coordinate transformation coefficient and the length of an element, respectively.

One can notice, that the enriched part of the approximation in blending elements is a quadratic function, whereas analytical solution is linear. For example in element 2 , the approximation formula consists of

$$
u^{2}(x)=\left(1-\frac{x-d^{2}}{l^{2}}\right) q_{2}+\frac{x-d^{2}}{l^{2}} q_{3}+\left|x-x^{*}\right| \frac{x-d^{2}}{l^{2}} a_{3}
$$

The quadratic term in the expression (19) cannot be compensated by the linear FE shape functions. In the reproducing element 3 the approximation formula takes the form

$$
u^{3}(x)=\left(1-\frac{x-d^{3}}{l^{3}}\right) q_{3}+\frac{x-d^{3}}{l^{3}} q_{4}+\left|x-x^{*}\right|\left(1-\frac{x-d^{3}}{l^{3}}\right) a_{3}+\left|x-x^{*}\right| \frac{x-d^{3}}{l^{3}} a_{4}
$$

In this case, the quadratic parts can be compensated if the condition $a_{3}=a_{4}$ is satisfied.

The solution obtained with standard XFEM without any modification in blending elements is shown in Fig. 7.
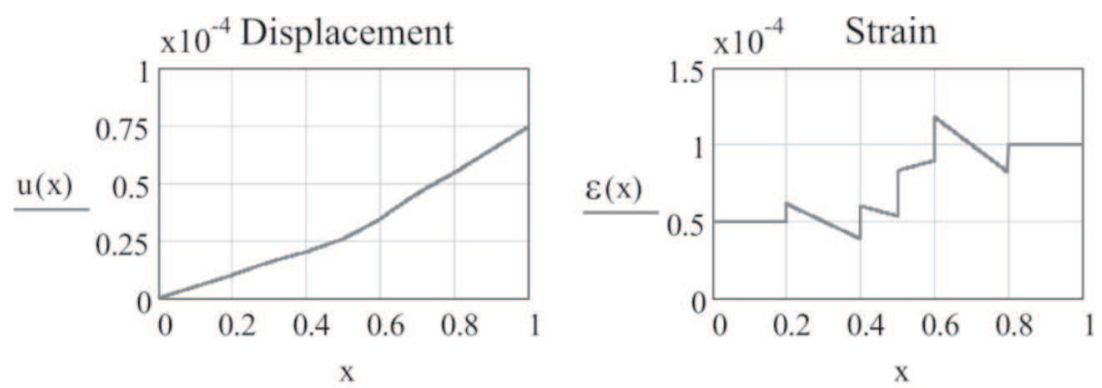

Fig. 7. Standard XFEM solution

As it seen from Fig. 7, the strain distribution exceeds acceptable error limits. 


\subsection{Modified XFEM solution}

Applying shifted-basis approximation redefines the global enrichment function in the following way

$$
\psi_{j}(x)=\left|x-x^{*}\right|-\left|x_{j}-x^{*}\right|
$$

Additionally, blending elements 2 and 4, are replaced with non-enriched elements. In this way, the PU condition is satisfied everywhere. In onedimensional case the continuity of displacement is fully preserved due to shifting the basis of enrichment function. This property allows us to reproduce linear solution in the overall domain. Results of computation are exactly the same as it is shown in Fig. 5. For this case, the modified XFEM gives the excellent results for any number of elements.

\section{Stress intensity factors computation}

To extract the stress intensity factors (SIFs), the well-known $J$-integral is used. For an arbitrary closed path $\Gamma$ around the tip of the crack, Fig. 8, the $J$-integral is given by

$$
J=\int_{\Gamma}\left(W \delta_{1 j}-\sigma_{i j} \frac{\partial u_{i}}{\partial x_{1}}\right) n_{j} \mathrm{~d} \Gamma
$$

where $W=\frac{1}{2} \sigma_{i j} \varepsilon_{i j}$ is strain energy, $n_{j}$ are the components of the unit vector normal to $\Gamma$ and $\delta_{1 j}$ is the Kronecker delta.

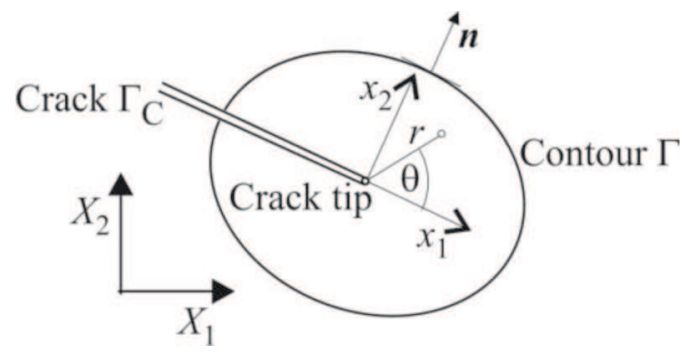

Fig. 8. Arbitrary contour around the tip of a crack

For a linear elastic material, the relation between $J$-integral and SIFs for mixed mode problem takes the form

$$
J=\frac{K_{I}^{2}+K_{I I}^{2}}{E^{*}}
$$

where $E^{*}=E$ for plane stress, and $E^{*}=E /(1-v)$ for plane strain condition. 
The calculation of the mixed mode SIFs requires superimposing two states of a cracked body. The state $1\left(\sigma_{i j}^{(1)}, \varepsilon_{i j}^{(1)}, u_{i}^{(1)}\right)$ is the actual state obtained from the XFEM analysis, and the state $2\left(\sigma_{i j}^{(2)}, \varepsilon_{i j}^{(2)}, u_{i}^{(2)}\right)$ is an auxiliary state. The auxiliary state is chosen to be the asymptotic fields for modes I and II, Anderson [1]. Inserting the sum of the actual and auxiliary states in the $J$-integral formula gives

$$
J=\int_{\Gamma}\left[\frac{1}{2}\left(\sigma_{i j}^{(1)}+\sigma_{i j}^{(2)}\right)\left(\varepsilon_{i j}^{(1)}+\varepsilon_{i j}^{(2)}\right)\right] n_{j}-\left[\left(\sigma_{i j}^{(1)}+\sigma_{i j}^{(2)}\right) \frac{\partial\left(u_{i}^{(1)}+u_{i}^{(2)}\right)}{\partial x_{1}}\right] n_{j} \mathrm{~d} \Gamma
$$

Rearranging terms in Eqn (24) leads to separation of the $J$-integral for the pure state $1 J^{(1)}$ and the auxiliary state $2 J^{(2)}$, from an interaction term $I^{(1,2)}$

$$
J=J^{(1)}+J^{(2)}+I^{(1,2)}
$$

The interaction integral for states 1 and 2 takes the form

$$
I^{(1,2)}=\int_{\Gamma}\left(W^{(1,2)} \delta_{1 j}-\sigma_{i j}^{(1)} \frac{\partial u_{i}^{(2)}}{\partial x_{1}}-\sigma_{i j}^{(2)} \frac{\partial u_{i}^{(1)}}{\partial x_{1}}\right) n_{j} \mathrm{~d} \Gamma
$$

where $W^{(1,2)}=\sigma_{i j}^{(1)} \varepsilon_{i j}^{(2)}$ is the interaction strain energy.

For combined states, Eqn (23) is

$$
J^{(1+2)}=\frac{\left(K_{I}^{(1)}\right)^{2}+\left(K_{I I}^{(1)}\right)^{2}}{E^{*}}+\frac{\left(K_{I}^{(2)}\right)^{2}+\left(K_{I I}^{(2)}\right)^{2}}{E^{*}}+\frac{2}{E^{*}}\left(K_{I}^{(1)}+K_{I}^{(2)}+K_{I I}^{(1)}+K_{I I}^{(2)}\right)
$$

Comparing Eqn (25) with Eqn (27) leads to the expression for the interaction integral expressed in terms of SIFs

$$
I^{(1,2)}=\frac{2}{E^{*}}\left(K_{I}^{(1)}+K_{I}^{(2)}+K_{I I}^{(1)}+K_{I I}^{(2)}\right)
$$

Assuming the state 2 as the pure mode I with $K_{I}^{(2)}=1$ and $K_{I I}^{(2)}=0$ enables one to solve Eqn (28) for mode I stress intensity factor of state 1

$$
K_{I}^{(1)}=\frac{E^{*}}{2} I^{(1, \text { Mode I })}
$$

The same approach is applied to find mode II stress intensity factor of state 1. Inserting $K_{I}^{(2)}=0$ and $K_{I I}^{(2)}=1$ to Eqn (28) leads to the following formula

$$
K_{I I}^{(1)}=\frac{E^{*}}{2} I^{(1, \text { Mode II })}
$$


Finite element calculation of the interaction integral, Eqn (26), needs to reformulate the integral into an area form. Introducing a smoothing function $\vartheta(\boldsymbol{x})$, which takes value of 1 on the innermost contour, and the value of 0 , on the outermost contour, and using the divergence theorem, give the fallowing equation for interaction integral

$$
I^{(1,2)}=\iint_{A}\left(\sigma_{i j}^{(1)} \frac{\partial u_{i}^{(2)}}{\partial x_{1}}+\sigma_{i j}^{(2)} \frac{\partial u_{i}^{(1)}}{\partial x_{1}}-W^{(1,2)} \delta_{1 j}\right) \frac{\vartheta(\boldsymbol{x})}{\partial x_{j}} \mathrm{~d} x_{1} \mathrm{~d} x_{2}
$$

Figure 9 shows elements selected around the crack tip and values of the smoothing function $\vartheta(\boldsymbol{x})$ for a domain radius $\mathrm{r}_{\mathrm{d}}$.

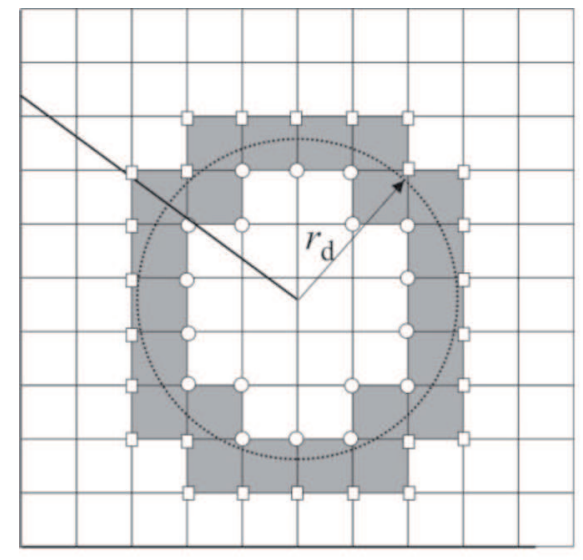

Transition layer

Nodes where $\mathrm{u}(\mathbf{x})=1$

$\square$ Nodes where $v(\mathbf{x})=0$

Fig. 9. Elements selected for calculation of the interaction integral

To approximate the smoothing function $\vartheta(x)$ inside elements, the standard FE shape functions are used

$$
\vartheta(x)=\sum_{i \in I} N_{i}(\boldsymbol{x}) \vartheta_{i}
$$

Since $\vartheta(\boldsymbol{x})=1$ in the interior elements, the derivatives of the smoothing function take the zero value for all elements inside the domain radius

$$
\frac{\partial \vartheta(\boldsymbol{x})}{\partial x_{j}}=\mathbf{0}
$$

Thus, the elements selected for calculation of the interaction integral are limited only to those which are cut by the contour $\Gamma$ (transition elements in Fig. 9). 


\section{Numerical examples}

\subsection{Beam with an edge crack}

The proposed approach has been applied to compute stress intensity factors for a beam in the plane stress state, with an edge crack, as shown in Fig. 10, where geometrical and material data for the test are also presented.

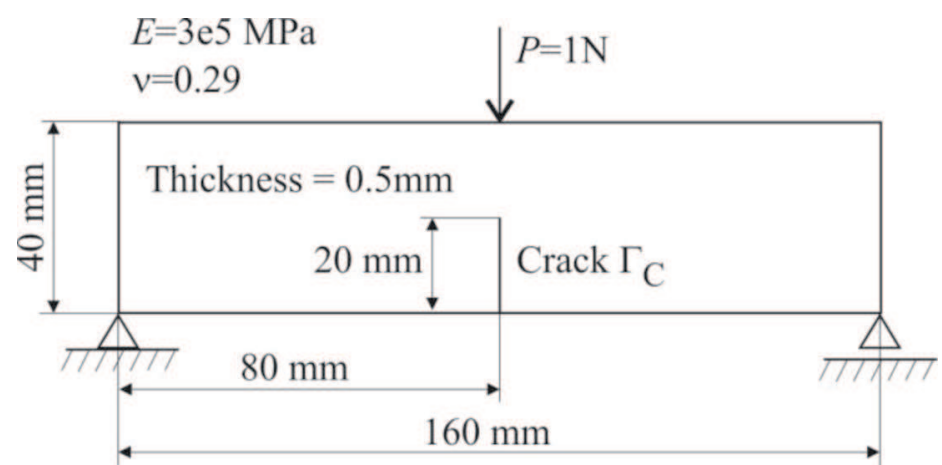

Fig. 10. Beam with an edge crack under concentrated force

The linear three-nodes finite elements are used. Deformed mesh with 313 elements is presented in Fig. 11, with the deformation scale factor set to $3 \cdot 10^{4}$.

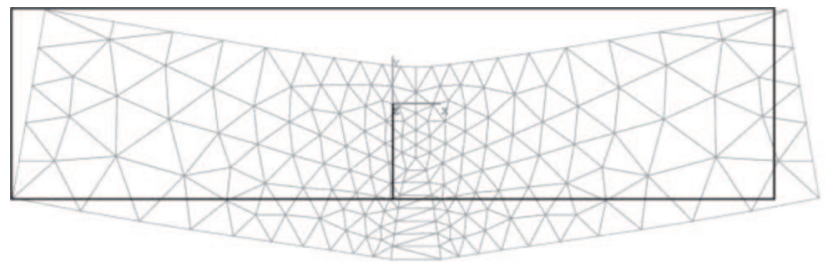

Fig. 11. Deformed mesh with 313 triangular elements

Numerical calculations of SIFs are carried out using the domain form of the interaction integral with a given domain size radius $r_{d}$. Table 1 shows the values of $K_{I}$ and the corresponding relative errors for standard and modified XFEM, calculated with the size of domain radius $r_{d}=10 \mathrm{~mm}$. The three different unstructured meshes are used in discretization, namely the coarse mesh with 313 triangular elements, medium mesh with 871 elements, and fine mesh with 2613 elements. The abbreviations XFEM s. and XFEM $\mathrm{m}$. mean standard and modified, respectively. 
Table 1.

Numerical results

\begin{tabular}{|c|c|c|c|c|}
\hline \multirow{2}{*}{$\begin{array}{c}\text { No. } \\
\text { of elements }\end{array}$} & \multicolumn{4}{|c|}{$K_{I}$} \\
\cline { 2 - 5 } & XFEM s. & Error & XFEM m. & Error \\
\hline 313 & 3.8069 & $13.64 \%$ & 3.2493 & $-3.00 \%$ \\
\hline 871 & 3.4674 & $3.50 \%$ & 3.2624 & $-2.61 \%$ \\
\hline 2613 & 3.4401 & $2.69 \%$ & 3.3447 & $-0.16 \%$ \\
\hline
\end{tabular}

The relative error in stress intensity factors is calculated as

$$
\text { Error }=\frac{K_{I}^{\text {Numerical }}-K_{I}^{\text {Theoretical }}}{K_{I}^{\text {Theoretical }}} 100 \%
$$

with the $K_{I}^{\text {Theoretical }}=3.35 M P a \sqrt{\mathrm{mm}}$.

The influence of the size of the domain radius $r_{d}$ on calculated values of the stress intensity factor $K_{I}$ is shown in Fig. 12.

—-XFEM s. $313 \mathrm{el}$.

$\checkmark$ XFEM s. $817 \mathrm{el}$.

$\nabla$ XFEM s. 2613 el.

* XFEM m. 313 el.

^ XFEM m. $817 \mathrm{el}$.

- XFEM m. 2613 el.

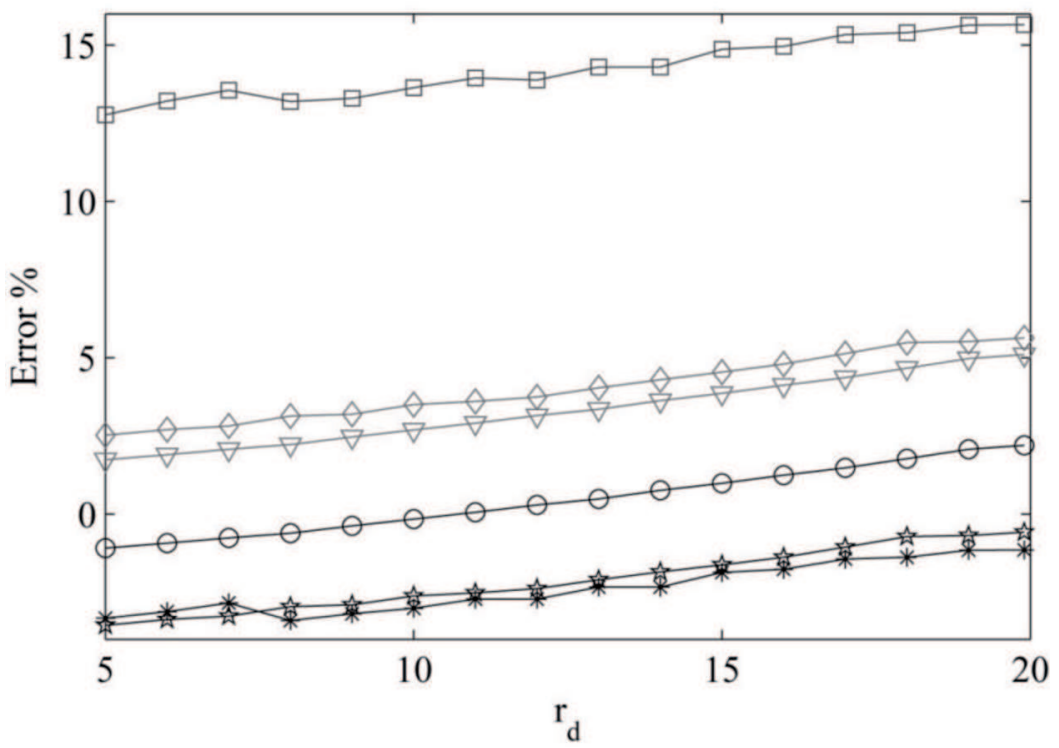

Fig. 12. Error in calculated values of vs. size of the domain radius 
As it is observed in this example, the relative error for standard approach with the medium mesh is comparable to the one obtained by the modified approach with the coarse mesh. Next, the modified XFEM with the medium mesh produces the comparable error to the standard XFEM with the fine mesh. Additionally, the standard approach overestimate the theoretical solution, whereas the modified approach underestimate it. The influence of the domain radius on the calculated SIF is similar for both approaches.

\subsection{Crack inclined at an angle}

The next investigated problem is a plate with an edge crack oriented at an angle $45^{\circ}$ to the loading direction. The plate is subjected to a uniformly distributed nominal stress $\sigma=1 \mathrm{~Pa}$. The geometry of the plate, material properties and an example of the structured mesh with nodes selected to be enriched are shown in Fig. 13.

The reference solution is obtained by finite element method with the use of the degenerated elements. The mesh aligns with the crack segment and consists 5193 nodes concentrated around the crack tip. The computed values of stress intensity factors for the reference problem are

$K_{I}^{\text {Theoretical }}=2.75917 \mathrm{~Pa} \sqrt{\mathrm{m}}, K_{I I}^{\text {Theoretical }}=1.23922 \mathrm{~Pa} \sqrt{\mathrm{m}}$.

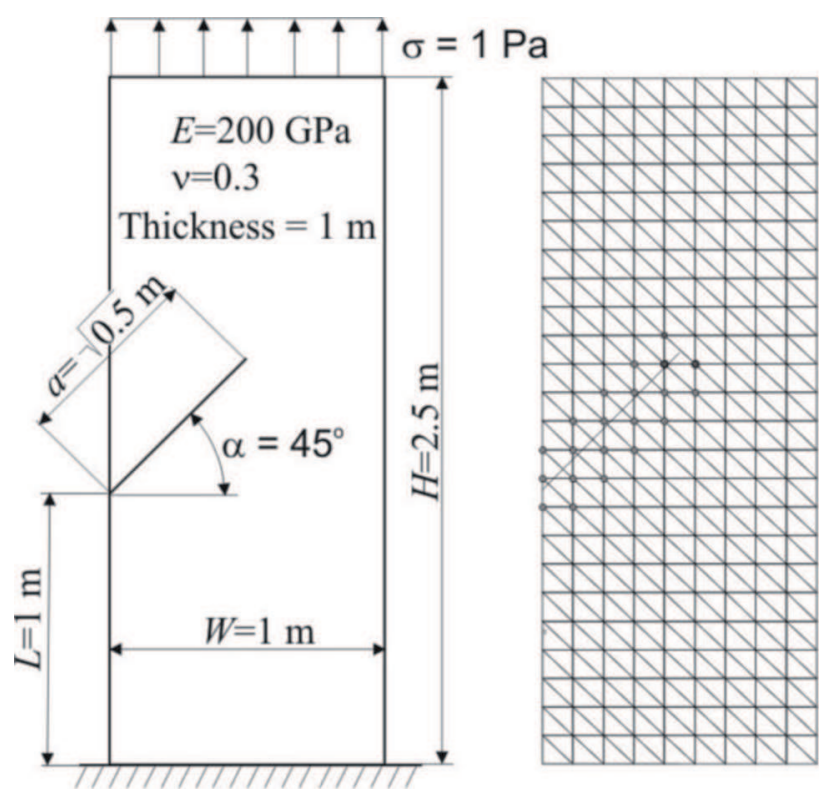

Fig. 13. Tension plate with an edge crack at an angle and a structured mesh with enriched nodes selected

Assessment of solution accuracy is made by evaluating the relative differences from reference solution according to Eqn (34) for three structured 
meshes. Tables 2 and 3 shows relative errors obtained for $K_{I}$ and $K_{I I}$, respectively.

Table 2 .

Numerical results: $K_{I}$ for angle crack

\begin{tabular}{|c|c|c|c|c|}
\hline \multirow{2}{*}{$\begin{array}{c}\text { No. } \\
\text { of nodes }\end{array}$} & \multicolumn{4}{|c|}{$K_{I}$} \\
\cline { 2 - 5 } & XFEM s. & Error & XFEM m. & Error \\
\hline 250 & 3.2658 & $18.36 \%$ & 2.9116 & $5.52 \%$ \\
\hline 490 & 3.1801 & $15.25 \%$ & 2.8706 & $4.03 \%$ \\
\hline 893 & 3.0291 & $9.78 \%$ & 2.7836 & $0.88 \%$ \\
\hline
\end{tabular}

Numerical results: $K_{I I}$ for angle crack

Table 3.

\begin{tabular}{|c|c|c|c|c|}
\hline \multirow{2}{*}{$\begin{array}{c}\text { No. } \\
\text { of nodes }\end{array}$} & \multicolumn{4}{|c|}{$K_{I I}$} \\
\cline { 2 - 5 } & XFEM s. & Error & XFEM m. & Error \\
\hline 250 & 1.3422 & $8.31 \%$ & 1.3550 & $9.34 \%$ \\
\hline 490 & 1.3320 & $7.48 \%$ & 1.3221 & $6.68 \%$ \\
\hline 893 & 1.2866 & $3.82 \%$ & 1.2434 & $0.33 \%$ \\
\hline
\end{tabular}

\section{Conclusions}

An improvement in results is observed when the transition layer of blending elements is eliminated, and at the same time, the shifted-basis approximation is applied. This improvement is clearly manifested in models with coarse meshes, even without any additional technique, e.g. point-wise matching, and even for the problems with a higher order enrichment function, like the near tip function in the crack analysis. Moreover, the proposed modification does not introduce any additional functions and degrees of freedom to the numerical model.

Manuscript received by Editorial Board, September 28, 2011; final version, January 02, 2012.

\section{REFERENCES}

[1] Anderson T.L.: Fracture Mechanics, Fundamentals and Application. third ed., Taylor \& Francis, Boca Raton-London-New York-Singapour, 2005.

[2] Belytschko T., Black T.: Elastic crack growth in finite elements with minimal remeshing. International Journal for Numerical Methods in Engineering, 1999, Vol. 45, pp. 601-620.

[3] Chessa J., Wang H.W., Belytschko T.: On the construction of blending elements for local partition of unity enriched finite elements. International Journal for Numerical Methods in Engineering, 2003, Vol. 57, pp. 1015-1038. 
[4] Fries T.P.: A corrected xfem approximation without problems in blending elements. International Journal for Numerical Methods in Engineering, 2008, Vol. 75, pp. 503-532.

[5] Laborde P., Pommier J., Renard Y., Salaun M.: High-order extended finite element method for cracked domains. International Journal for Numerical Methods in Engineering, 2005, Vol. 64, No. 3, pp. 354-381.

[6] Möes N., Dolbow J., Belytschko T.: A finite element method for crack growth without remeshing. International Journal for Numerical Methods in Engineering, 1999, Vol. 46, pp. 131-150.

[7] Rice J.R.: A Path Independent Integral and the Approximate Analysis of Strain Concentration by Notches and Cracks. Journal of Applied Mechanics, 1968, Vol. 35, pp. 379-387.

[8] Tarancòn J.E.: Enhanced blending elements for XFEM applied to LEFM. International Journal for Numerical Methods in Engineering, 2009, Vol. 77, pp. 126-148.

[9] Ventura G., Budyn E., Belytschko T.: Vector level sets for description of propagating cracks in finite elements. International Journal for Numerical Methods in Engineering, 2003, Vol. 58, pp. 1571-1592.

[10] Yau J., Wang S., Corten H.: A mixed-mode crack analysis of isotropic solids using conservation laws of elasticity. Journal of Applied Mechanics, 1980, Vol. 47, pp. 335-341.

[11] Zi G., Belytschko T.: New crack-tip elements for XFEM and applications to cohesive cracks. International Journal for Numerical Methods in Engineering, 2003, Vol. 57, pp. 2221-2240.

\section{Obliczanie współczynników intensywności naprężeń rozszerzoną metodą elementów skończonych z przesunięciem bazy aproksymacyjnej}

\section{Streszczenie}

Kluczowymi parametrami oceny wytrzymałości konstrukcji w liniowo sprężystej mechanice pękania są współczynniki intensywności naprężeń (ang. SIFs). Analityczne metody wyznaczania tych współczynników ograniczone są do nieskomplikowanych konstrukcji. Jedną z technik numerycznych pozwalających na efektywną analizę problemów z osobliwymi polami jest rozszerzona metoda elementów skończonych (ang. XFEM).

W pracy zastosowano rozszerzoną metodę elementów skończonych do wyznaczania pól naprężeń w dwu-wymiarowym ośrodku ciągłym z rysą. Zaproponowano modyfikacje standardowego podejścia poprzez usunięcie z przestrzeni aproksymacji elementów częściowo wzbogaconych (ang. blending elements) $\mathrm{z}$ jednoczesnym przesunięciem bazy aproksymacyjnej $\mathrm{w}$ elementach z pełnym wzbogaceniem węzłów. Do obliczania współczynników intensywności naprężeń zastosowano znaną w mechanice pękania definicję całki $J$. W rozwiązywanych przykładowych problemach zaobserwowano polepszenie wartości obliczanych współczynników intensywności naprężeń w porównaniu do standardowego podejścia z tą samą dyskretyzacją. 